\title{
A 192 bp ERV fragment insertion in the first intron of porcine TLR6 may act as an enhancer associated with the increased expressions of TLR6 and TLR1
}

\author{
XiaoYan Wang ${ }^{1}$, Zixuan Chen ${ }^{1}$, Eduard Murani ${ }^{2}$, Enrico D'Alessandro ${ }^{3}$, Yalong An ${ }^{1}$, Cai Chen ${ }^{1}$, Kui Li ${ }^{4}$, \\ Grazia Galeano ${ }^{3}$, Klaus Wimmers ${ }^{2}$ and Chengyi Song ${ }^{1 *}$
}

\begin{abstract}
Background: Toll-like receptors (TLRs) play important roles in building innate immune and inducing adaptive immune responses. Associations of the TLR genes polymorphisms with disease susceptibility, which are the basis of molecular breeding for disease resistant animals, have been reported extensively. Retrotransposon insertion polymorphisms (RIPs), as a new type of molecular markers developed recently, have great potential in population genetics and quantitative trait locus mapping. In this study, bioinformatic prediction combined with PCR-based amplification was employed to screen for RIPs in porcine TLR genes. Their population distribution was examined, and for one RIP the impact on gene activity and phenotype was further evaluated.

Results: Five RIPs, located at the 3' flank of TLR3, 5' flank of TLR5, intron 1 of TLR6, intron 1 of TLR7, and 3' flank of TLR8 respectively, were identified. These RIPs were detected in different breeds with an uneven distribution among them. By using the dual luciferase activity assay a 192 bp endogenous retrovirus (ERV) in the intron 1 of TLR6 was shown to act as an enhancer increasing the activities of TLR6 putative promoter and two mini-promoters. Furthermore, realtime quantitative polymerase chain reaction (qPCR) analysis revealed significant association $(p<0.05)$ of the ERV insertion with increased mRNA expression of $T L R 6$, the neighboring gene $T L R 1$, and genes downstream in the TLR signaling pathway such as MyD88 (Myeloid differentiation factor 88), Rac1 (Rac family small GTPase 1), TIRAP (TIR domain containing adaptor protein), Tollip (Toll interacting protein) as well as the inflammatory factors IL6 (Interleukin 6), IL8 (Interleukin 8), and TNFa (Tumor necrosis factor alpha) in tissues of 30 day-old piglet. In addition, serum IL6 and TNFa concentrations were also significantly upregulated by the ERV insertion $(p<0.05)$.
\end{abstract}

Conclusions: A total of five RIPs were identified in five different TLR loci. The $192 \mathrm{bp}$ ERV insertion in the first intron of $T L R 6$ was associated with higher expression of $T L R 6, T L R 1$, and several genes downstream in the signaling cascade. Thus, the ERV insertion may act as an enhancer affecting regulation of the TLR signaling pathways, and can be potentially applied in breeding of disease resistant animals.

Keywords: Pig, Retrotransposon, RIP, ERV, TLRs, TLR6, Enhancer, Expression, Polymorphism

${ }^{*}$ Correspondence: cysong@yzu.edu.cn

${ }^{1}$ College of Animal Science \& Technology, Yangzhou University, Yangzhou 225009, Jiangsu, China

Full list of author information is available at the end of the article

\section{Background}

Toll-like receptors (TLRs) play vital roles in innate and adaptive immune responses due to their ability to recognize different types of pathogens and associated original author(s) and the source, provide a link to the Creative Commons licence, and indicate if changes were made. The images or other third party material in this article are included in the article's Creative Commons licence, unless indicated otherwise in a credit line to the material. If material is not included in the article's Creative Commons licence and your intended use is not permitted by statutory regulation or exceeds the permitted use, you will need to obtain permission directly from the copyright holder. To view a copy of this licence, visit http://creativecommons.org/licenses/by/4.0/. The Creative Commons Public Domain Dedication waiver (http://creativeco mmons.org/publicdomain/zero/1.0/) applies to the data made available in this article, unless otherwise stated in a credit line to the data. 
molecular patterns and activate immune-related signaling pathways [1]. Polymorphisms in TLR loci and their influence on either susceptibility or resistance to major human infectious diseases, including tuberculosis, leishmaniasis, malaria, filariasis and some autoimmune endocrine diseases, have been reported extensively [2-4]. It has been reported that C1174T substitution in TLR5 resulting in a stop codon polymorphism causes significantly lower levels of proinflammatory cytokines in comparison to individuals with the wild-type genotype and that the TLR5 stop codon polymorphism is associated with protection from the development of systemic lupus erythematosus [5]. The missense mutation rs5743618 in TLR1, specific for Europeans, can change the expression of 81 genes involved in the inflammatory response [6]. Chikungunya patients with rs179010-CC genotype of TLR7 showed significantly higher interferon alpha 1 (IFN $\alpha$ ) level, which might act as potential prognostic biomarkers for predicting Chikungunya susceptibility [7]. It is commonly accepted that TLRs are important candidate genes for some human immune diseases.

For domesticated farm animals, TLRs also have been suggested as the most promising candidate genes for improvement of immune response or disease resistance by molecular breeding [8]. Genetic variants of TLRs associated with cattle mastitis, mycobacterial infection, and paratuberculosis have been identified [9-11]. In pigs, ten TLRs were annotated in the genome, and a number of studies reported on SNP screening of the porcine TLRs and their expression patterns in immune response-related organs [12]. C506W substitution in TLR4 cDNA in Japanese segregating in wild boar populations caused loss of ability to induce nuclear factor kappa B subunit (NF-kB) activation after lipid A stimulation [13]. Association between SNPs in TLR4 and TLR5 with transcript abundance of cytokine genes indicates that these SNPs are related to the modulation of the cytokine mediated immune response [14, 15]. Recently, genetic variation in all 10 TLRs across 11 pig breeds was screened by using targeted subgenome enrichment and high-throughput sequencing, and 306 SNPs were discovered [16]. In another report, a total of 136 SNPs was obtained by sequencing TLR1, TLR2, TLR6, TLR3, TLR7, and TLR8 genes, and a variant G376A( Ala126Thr) in TLR2 was identified to be under positive selection in pigs of European origin. A 3D crystal structure analysis revealed that this SNP (G376A) may affect ligand binding, indicating that TLR2 may contribute to responses to bacterial pathogens, and play an important role in adaptation of pigs to pathogens [17]. It has been suggested that piglets with the $\mathrm{T}$ allele of a C1205T substitution in TLR5 cDNA exhibit impaired resistance to Salmonella typhimurium infection [18]. So far, all association studies of TLRs with diseases susceptibility were based on SNPs, however reports on retrotransposon insertion polymorphisms in TLRs and their genetic effects are not available.

Retrotransposons are important components of plant and animal genomes, accounting for nearly half of the mammalian genomes $[19,20]$, and can mobilize themselves to new genomic locations and generate polymorphic insertions. Retrotransposons can be classified into LTR (Long Terminal Repeat elements, including endogenous retrovirus, ERV) and non-LTR families (including LINE, Long Interspersed Nuclear Elements; and SINE, Short Interspersed Nuclear Elements) [21]. For a long time, transposable elements including retrotransposon have been considered as genomic parasites and 'junk DNA' $[22,23]$. However, mounting evidence suggests that retrotransposons contribute to genome architecture and evolution, and even maintenance of three-dimensional chromatin organization in mammals [20, 24-26].

Retrotransposon insertion polymorphisms (RIPs) have been applied as molecular markers to study genome evolution and genetic diversity in plants [27, 28]. In humans, RIPs have been identified as causative mutations for some diseases [29]. Genome-wide association studies revealed an intronic Alu insertion polymorphism in CD58 gene associated with multiple sclerosis risk possibly due to altering its mRNA splicing [30, 31]. In domestic animals, RIPs also have been used for evolution and population genetic analysis in sheep [32], cat [33], chicken [34], and rabbit [35]. Several RIPs have been associated with phenotypic variation in farm animals, such as an ERV insertion in the 5' flanking region of SLCO1B3 causing blue eggshell by promoting the expression of the SLCO1B3 gene in the uterus (shell gland) of the oviduct in chicken [36, 37], the henny feathering allele harboring an insertion of an intact avian ERV at the 5'end of CYP19A1 [38], and the SINE insertions in the follicle stimulating hormone beta $(F S H \beta)$ and the protein disulfide isomerase associated 4 (PDIA4) genes associated with litter size variations in pigs $[39,40]$.

In the present study, the contribution of RIPs to the structural variations of TLR genes, the breed distribution of these RIPs and the genetic effects of one RIP were investigated. We identified five RIPs, each in a different $T L R$ gene, and our data suggest that one RIP may play a role in the regulation of the TLR signaling pathway by acting as an enhancer. These findings will contribute to the understanding of the role of RIPs in shaping the pig genomic and genetic variation, and one RIP may be useful for molecular breeding to improve disease resistance in the pig. 


\section{Results}

Five RIPs generated by retrotransposon insertions in the pig TLR gene cluster

Ten $T L R$ genes and their flanking sequences from sixteen assembled pig genomes, representing lean type pigs (Cross-breed of Yorkshire/Landrace/Duroc, Duroc, Landrace, Yorkshire, Pietrain, Berkshire, and Hampshire), fat type pigs (Rongchang, Meishan, Bamei, and Jinhua), and miniature pigs (Bama, Wuzhishan, Tibetan, Goettingen, and Ellegaard Gottingen) were used to screen for structural variations by sequence alignment using the ClustalX program [41]. In total, we identified 53 large structural variations (SVs, defined as variants more than $50 \mathrm{bp}$ and less than $1000 \mathrm{bp}$ long) or large frameshift variants (more than $1000 \mathrm{bp}$ long), and 32 of them were predicted as RIPs, including 15 SINE, 11 ERV, and 6 LINE RIPs, which were summarized in additional file 1 (Table S1). Then all these predicted RIPs were further experimentally evaluated by PCR screening of pooled DNA samples of 11 domesticated pig breeds and wild boar using specific primer pairs spanning the insertions. Five RIPs, including two SINE RIPs, two ERV RIPs and one LINE RIP, were confirmed by the PCR screening (Fig. 1A). All these RIPs were further confirmed by TA cloning and Sanger sequencing. One $288 \mathrm{bp}$ and one $294 \mathrm{bp}$ SINE RIPs in the 3' flanking sequence of TLR3 and TLR8 were detected, respectively. Moreover, a single 357 bp LINE RIP in the 5' flanking region of TLR5 was found as well as one $192 \mathrm{bp}$ and one 413 bp ERV RIPs in first intron of TLR6 and $T L R 7$, respectively. We named those insertions as TLR3SINE-RIP, TLR5-LINE-RIP, TLR6-ERV-RIP, TLR7-ERVRIP, and TLR8-SINE-RIP, respectively (Fig. 1B and 1C).

\section{RIP distribution in different pig breeds}

For the confirmed RIPs (Fig. 1A) their segregation was examined in individual samples of the twelve different breeds. Furthermore, TLR6-ERV-RIP was evaluated in three additional populations (Landrace and Yorkshire from Germany and Sicilian Black from Italy). Detailed information (including the number of animals used,

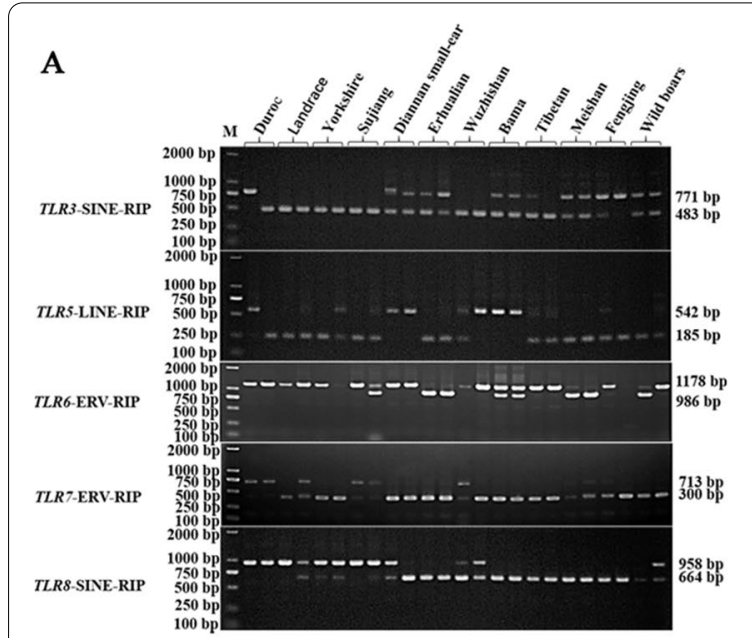

B

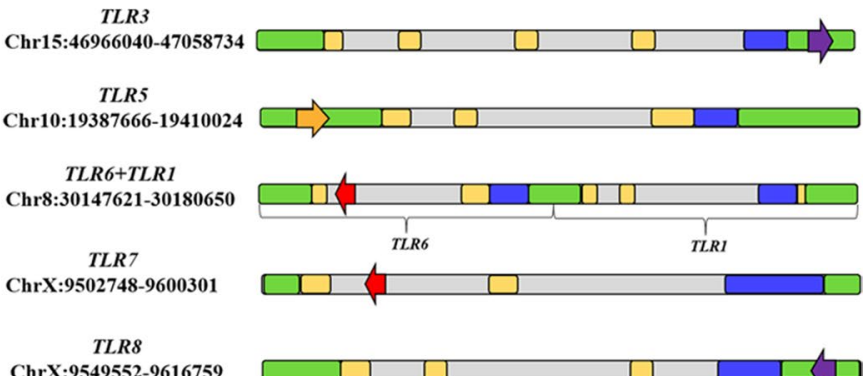

ChrX:9549552-9616759

Flank $\square$ EXON CDs $\Rightarrow$ SINE $\Rightarrow$ LINE $\Rightarrow$ ERV

C

\begin{tabular}{cccccc}
\hline Name & Family & Length & Location & Direction & polymorphic breeds in DNA pool \\
\hline SINE-RIP-TLR3 & SINE A1 & $288 \mathrm{bp}$ & 3' Flank & + & $\begin{array}{c}\text { Duroc, Diannan small-ear, Erhualian, Bama, Tibetan, Meishan, } \\
\text { Fengjing, Wild boars }\end{array}$ \\
LINE-RIP-TLR5 & LINE L1 & $357 \mathrm{bp}$ & 5' Flank & + & Duroc, Yorkshire, Wuzhishan \\
ERV-RIP-TLR6 & ERV18 & $192 \mathrm{bp}$ & Intron 1 & - & Sujiang, Bama, Fengjing, Wild boars \\
ERV-RIP-TLR7 & ERV6A & $413 \mathrm{bp}$ & Intron 1 & - & $\begin{array}{c}\text { Landrace, Wuzhishan } \\
\text { SINE-RIP-TLR8 }\end{array}$ \\
\hline
\end{tabular}

Fig. 1 PCR identification and characteristic of RIP in TLRs. a RIPs were identified in DNA pool by PCR; b Location of RIPs in TLRs; c Characteristic of RIPS in TLRS 
breed origins, and genotype and allele frequency) for each breed is summarized in Table 1. The results of PCR genotyping confirmed that all RIPs in these breeds are polymorphic, i.e. both alleles $\left(\mathrm{RIP}^{ \pm}\right)$were detected, except for TLR6-ERV-RIP which proved to be monomorphic in Sicilian Black pigs from Italy, and Landrace and Yorkshire from Germany. For the most part genotype distribution of the RIPs was in HardyWeinberg equilibrium $(p>0.05)$, while TLR3-SINE-RIP in Meishan, TLR6-ERV-RIP in Sujiang, Erhualian and Fengjing, TLR7-ERV-RIP in Landrace, TLR8-SINERIP in Wuzhishan deviated from the Hardy-Weinberg equilibrium $(p<0.05)$. The SINE ${ }^{+/+}$genotype of TLR3SINE-RIP in Duroc and Tibetan, the ERV ${ }^{-l-}$ genotype of TLR6-ERV-RIP in Fengjing, and the ERV ${ }^{+/+}$genotype of TLR7-ERV-RIP in Landrace and Wuzhishan were not detectable. In most breeds the RIPs displayed moderate polymorphic information content (PIC, ranging from 0.239 to 0.375 ), except for Duroc and Tibetan, where TLR3-SINE-RIP shows low PIC values (low than $0.150)$.
Evidence of enhancer activity of the $192 \mathrm{bp}$ ERV insertion Both of TLR6 and TLR7 genes contain an ERV insertion in the first intron, and further analysis revealed that the 192 bp ERV insertion in intron 1 of TLR6 resides between two putative promoters (988 bp upstream and $453 \mathrm{bp}$ downstream to the ERV insertion), with high prediction scores $(>1)$ by Promoter 2.0, BDGP, and ENCODE. The 192 bp ERV was a truncated LTR fragment of ERV18 (Fig. 2A), which was identified as a beta ERV, and is located close to the human HERV-K as revealed by phylogenetic analysis [42]; only one intact copy (100\% identity and $100 \%$ coverage), but about 800 homologous copies (sequence identity $>85 \%$ and coverage $>70 \%$ ) of the 192 bp ERV insertion were identified in the porcine genome by BLAST search (Fig. 2B). The sequence between nucleotides $20-50$ and $90-120$ of the 192 bp ERV fragment is enriched for transcription factor binding motifs. To further evaluate the potential involvement of the ERV insertion in the regulation of promoter activity of TLR6, alternative genomic fragments, either containing (1187 bp) or lacking (995 bp) the $192 \mathrm{bp}$ ERV insertion, were cloned into a luciferase reporter vector

Table 1 Genotype and allele frequency of five RIPs in the RIP-polymorphic breeds

\begin{tabular}{|c|c|c|c|c|c|c|c|c|c|}
\hline \multirow[t]{2}{*}{ RIP } & \multirow[t]{2}{*}{ Breed } & \multirow[t]{2}{*}{$\mathrm{N}$} & \multicolumn{3}{|c|}{ Genotype/\% } & \multicolumn{2}{|c|}{ Allele/\% } & \multirow[t]{2}{*}{ Hardy-Weinberg/P } & \multirow[t]{2}{*}{ PIC } \\
\hline & & & $+/+$ & \pm & $-/-$ & + & - & & \\
\hline \multirow[t]{6}{*}{ TLR3-SINE-RIP } & Duroc & 24 & 0 & 16.67 & 83.33 & 8.33 & 91.67 & 0.656 & 0.141 \\
\hline & Erhualian & 24 & 25.00 & 45.83 & 29.17 & 47.92 & 52.08 & 0.689 & 0.375 \\
\hline & Bama & 30 & 3.33 & 60.00 & 36.67 & 33.33 & 66.67 & 0.552 & 0.346 \\
\hline & Tibetan & 35 & 0 & 17.14 & 82.86 & 8.57 & 91.43 & 0.579 & 0.144 \\
\hline & Meishan & 24 & 37.50 & 29.17 & 33.33 & 52.08 & 47.92 & 0.042 & 0.375 \\
\hline & Fengjing & 23 & 47.83 & 39.13 & 13.04 & 67.39 & 32.61 & 0.599 & 0.343 \\
\hline \multirow[t]{3}{*}{ TLR5-LINE-RIP- } & Duroc & 24 & 4.17 & 62.50 & 33.33 & 35.42 & 64.58 & 0.073 & 0.353 \\
\hline & Yorkshire & 24 & 8.33 & 41.67 & 50 & 29.17 & 70.83 & 0.967 & 0.328 \\
\hline & Wuzhishan & 24 & 29.17 & 50.00 & 20.83 & 54.17 & 45.83 & 0.973 & 0.373 \\
\hline \multirow[t]{7}{*}{ TLR6-ERV-RIP } & Sujiang & 163 & 52.76 & 20.86 & 26.38 & 63.19 & 36.81 & $1.89^{\mathrm{e}-12}$ & 0.357 \\
\hline & Erhualian & 36 & 27.78 & 22.22 & 50.00 & 38.89 & 61.11 & 0.001 & 0.362 \\
\hline & Bama & 43 & 44.19 & 39.53 & 16.28 & 63.95 & 36.05 & 0.350 & 0.355 \\
\hline & Fengjing & 24 & 41.67 & 58.33 & 0 & 70.83 & 29.17 & 0.044 & 0.328 \\
\hline & Yorkshire (German) & 31 & 100 & 0 & 0 & 100 & 0 & 1 & 0 \\
\hline & Sicilian black (Italy) & 30 & 100 & 0 & 0 & 100 & 0 & 1 & 0 \\
\hline & Landrace (German) & 32 & 100 & 0 & 0 & 100 & 0 & 1 & 0 \\
\hline \multirow[t]{2}{*}{ TLR7-ERV-RIP } & Landrace & 18 & 0 & 83.33 & 16.67 & 41.67 & 58.33 & 0.002 & 0.368 \\
\hline & Wuzhishan & 23 & 0 & 43.48 & 56.52 & 21.74 & 78.26 & 0.183 & 0.282 \\
\hline \multirow[t]{4}{*}{ TLR8-SINE-RIP } & Landrace & 24 & 75.00 & 16.67 & 8.33 & 83.33 & 16.67 & 0.050 & 0.239 \\
\hline & Yorkshire & 24 & 62.50 & 29.17 & 8.33 & 77.08 & 22.92 & 0.393 & 0.291 \\
\hline & Sujiang & 24 & 50.00 & 45.83 & 4.17 & 72.92 & 27.08 & 0.432 & 0.317 \\
\hline & Wuzhishan & 23 & 43.48 & 26.09 & 30.43 & 56.52 & 43.48 & 0.024 & 0.371 \\
\hline
\end{tabular}

Only the breeds displaying polymorphic RIPs in Fig. 1A were used for further RIP distribution evaluation by increasing individuals except Diannan small-ear pig, Sicilian black from Italy and Landrace and the Yorkshire from Germany were used for TLR6-ERV-RIP evaluation. Polymorphic information content (PIC) was measured by using the formula as described in Materials and Methods. The Hardy-Weinberg was detected by and the $p<0.05$ indicates that the RIP distribution is deviated from the Hardy-Weinberg equilibrium 


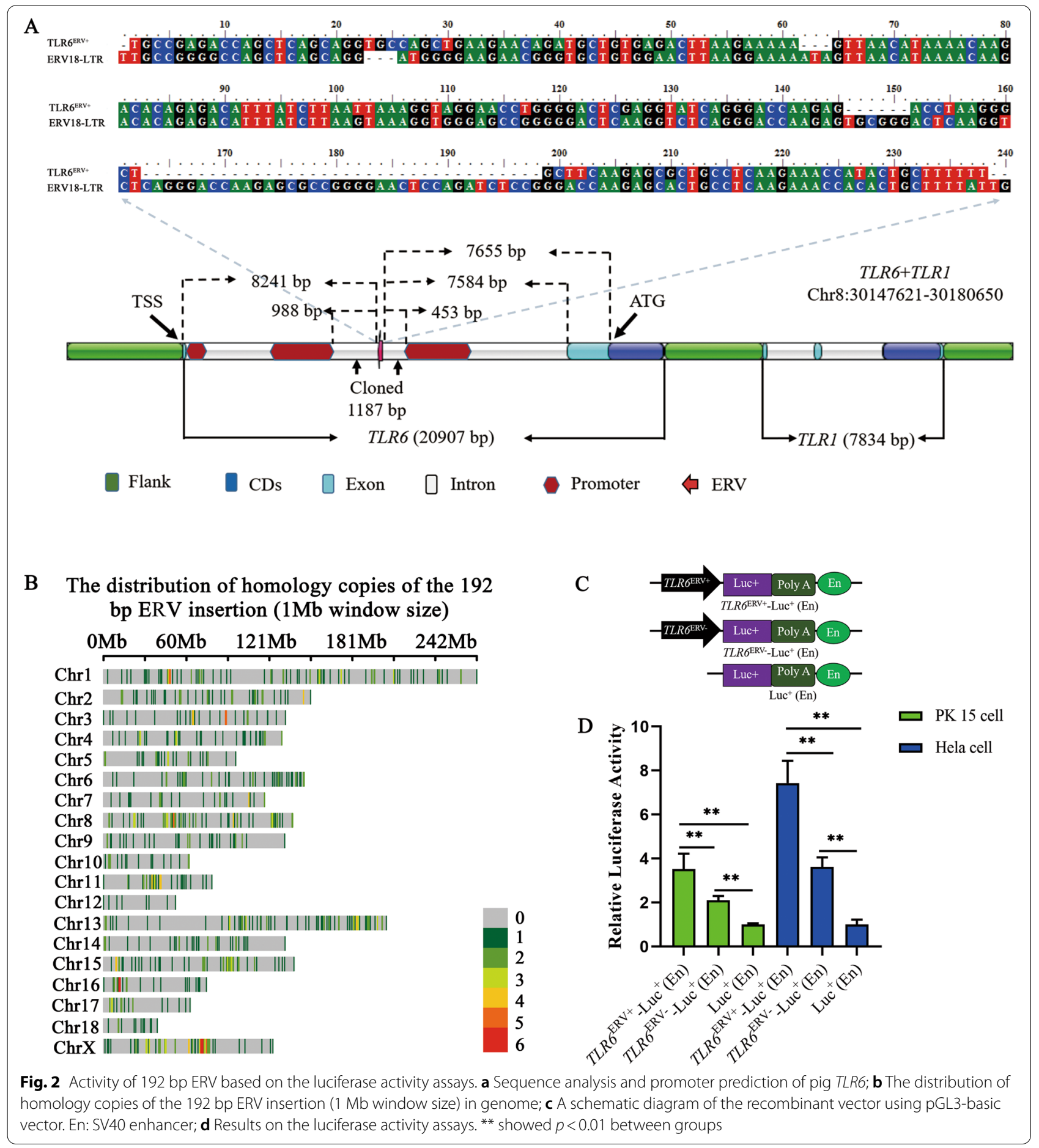

(pGL3-basic) respectively (Fig. 2C), and then submitted to luciferase activity evaluation. The dual luciferase activity assay revealed that the genomic fragment lacking the ERV insertion allele (995 bp) displayed considerable promoter activity compared with the control vector (pGL3-basic), while the ERV insertion significantly enhanced its activity $(p<0.01)$. The luciferase activity in cells transfected with the vector of TLR6 $6^{\mathrm{ERV}+}$-Luc (En), which contains the ERV insertion, were almost two times higher $(p<0.01)$ than that in cells transfected with the vector of TLR6 ${ }^{\mathrm{ERV}-}$ Luc (En) without the ERV insertion allele in both porcine PK15 and human Hela cells (Fig. 2D), which suggested 
that the 192 bp ERV may act as an enhancer in the regulation of TLR6 promoter activity. To further confirm this conclusion, we evaluated the enhancer activity of the ERV insertion by cloning this into the luciferase reporter vector containing a mini-promoter, but without the SV40 enhancer, which is generally used for enhancer activity evaluation. Two types of mini-promoters ( $\beta$-globin and Oct4) were evaluated, and the outline of the vectors is presented in Fig. 3A and B. Again, the luciferase activity assay revealed that the ERV insertion allele significantly enhances all these mini-promoter activities in both Hela (Fig. 3C) and PK15 cell lines (Fig. 3D) $(p<0.05)$. These data strongly suggest that the $192 \mathrm{bp}$ ERV insertion acts as an enhancer involved in the regulation of TLRs.

\section{ERV insertion alters the expression of pig TLR6 and TLR1 and their downstream genes in multiple tissues}

To further characterize the biological roles of the $192 \mathrm{bp}$ ERV insertion in the TLR signaling pathway, we investigated the mRNA expression of TLR6 and TLR1, which are neighboring genes located on chromosome 8 , and genes downstream in the same pathway (MyD88, Rac1,
Tollip, TIRAP, IL6, IL8, and TNF $\alpha$ ) depending on genotype of the RIP in multiple tissues (liver, spleen, lung and kidney) of 30 day-old piglets using qPCR. The qPCR results revealed that, generally, the ERV insertion was associated with higher expression of TLR6 and TLR1 in these tissues. In detail, in the spleen, kidney and liver tissues, the expression of TLR6 and TLR1 in the pigs with $\mathrm{ERV}^{+/+}$genotype were significantly higher $(p<0.05)$ than that in those animals with ERV ${ }^{ \pm}$and $\mathrm{ERV}^{-/-}$genotypes. In lung, there were significant expression differences $(p<0.01)$ of TLR6 between the ERV $V^{+/+}$animals and the ERV $^{-1-}$ animals (Fig. 4A and 4B). The qPCR analysis of MyD88, Rac1, Tollip and TIRAP expression revealed that ERV insertion was associated with enhanced expressions for most of them. In detail, in the spleen, lung and kidney, the expression levels of $M y D 88$ and Rac1 were significantly higher $(p<0.05)$ in the animals with $\mathrm{ERV}^{+/+}$ than in the animals with $\mathrm{ERV}^{-1-}$ genotype (Fig. $4 \mathrm{C}$ and 4D). Expression of TIRAP and TOLLip in liver, lung and kidney of $\mathrm{ERV}^{+/+}$homozygous animals were significantly $(p<0.05)$ higher than those of heterozygote $\left(E R V^{ \pm}\right)$and homozygote $\left(\mathrm{ERV}^{-l-}\right)$ animals (Fig. $4 \mathrm{E}$ and $\left.4 \mathrm{~F}\right)$. In spleen,

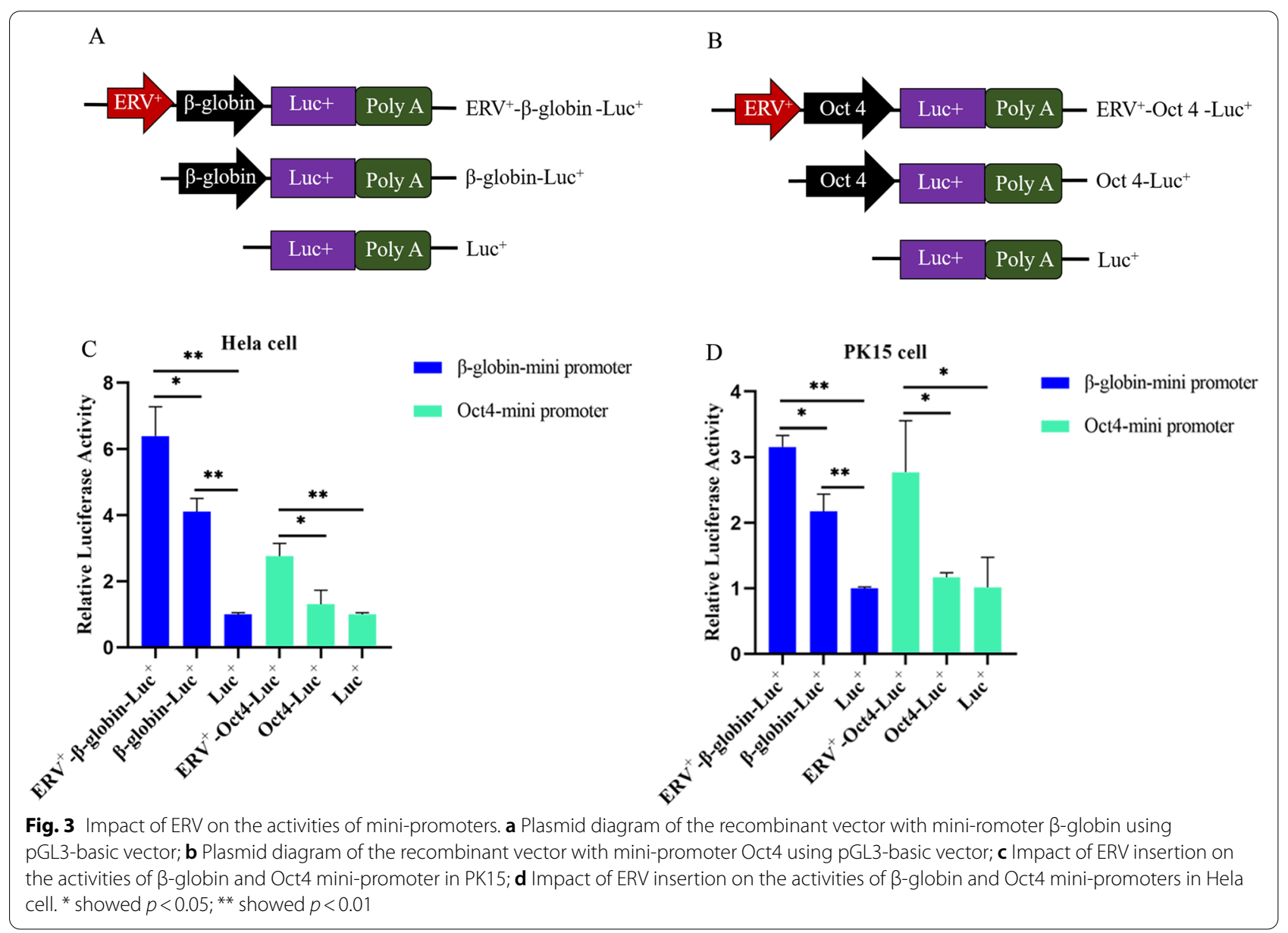



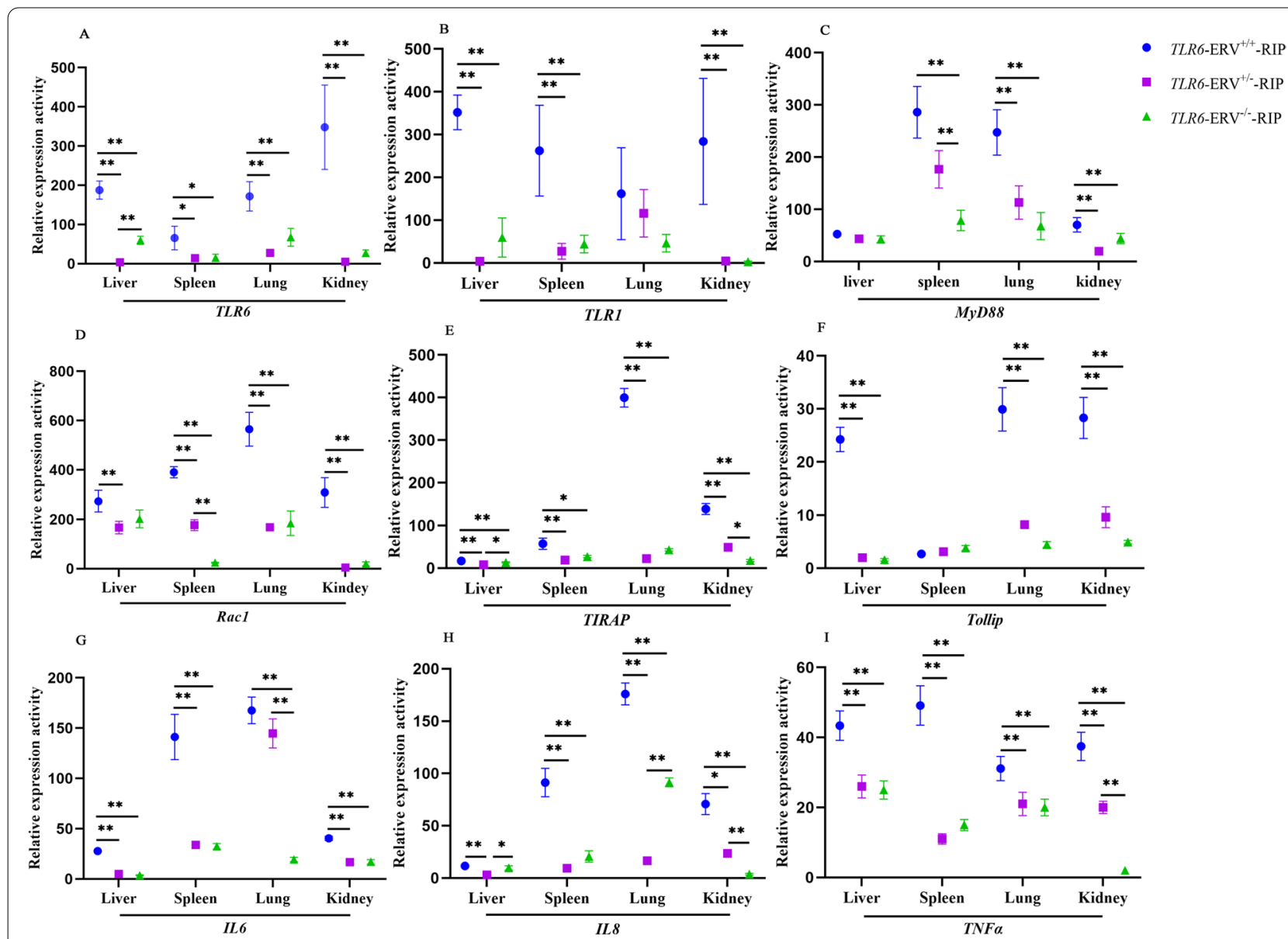

Fig. 4 Impact of ERV insertion on expression of TLR6 (A), TLR1 (B) and downstream genes MyD88 (C), Racl (D), TIRAP (E), TOllip (F), IL6 (G), IL8 (H), TNFa (I) of TLR signaling pathway in different tissues of 30-day old piglets. Five piglets for each genotype (ERV ${ }^{+/+}$, ERV ${ }^{ \pm}$, and ERV ${ }^{-/-}$) were selected for qPCR. All measurements were performed in 3 replicates for each individual. GAPDH was used to normalize the target genes expression. Values shown are mean \pm SD. * showed $p<0.05 ;{ }^{* *}$ showed $p<0.01$

significant $(p<0.05)$ difference was observed for the expression of TIRAP gene between homozygotes $\mathrm{ERV}^{+/+}$ and $\mathrm{ERV}^{-1-}$ or heterozygote $\mathrm{ERV}^{ \pm}$animals (Fig. 4E). Inflammatory factors $I L 6, I L 8, T N F \alpha$ are important genes at the end of TLR signaling pathway. The expression of $T N F \alpha, I L 6, I L 8$ increased significantly $(p<0.05)$ in the spleen, lung and kidney of homozygous of $\mathrm{ERV}^{+/+} \mathrm{com}-$ pared with that in $\mathrm{ERV}^{-/-}$genotype piglets (Fig. 4G, 4H, 4I). These results indicated that the 192 bp ERV insertion allele near the core promoter of TLR6 is associated not only with increased expression of TLR6 and TLR1, but also with the expression levels of the downstream genes of the TLR signaling pathway.

\section{Impact of ERV insertion on the serum immune cytokine}

To investigate the impact of the ERV insertion allele near the core promoter of TLR6 on the immune response, several serum immune cytokines were measured by ELISA in 30 day-old piglets. The ELISA analysis revealed that, consistent with the higher expression of IL6 and TNFa in the important immune tissues (spleen and kidney) of $\mathrm{ERV}^{+/+}$piglets compared to other genotypes $\left(\mathrm{ERV}^{ \pm}\right.$and $\mathrm{ERV}^{-/-}$), the serum concentrations of IL6 and TNF $\alpha$ in the animals with $\mathrm{ERV}^{+/+}$genotype were also significantly higher than that in the ERV ${ }^{-/}$genotype animals $(p<0.05)$ (Fig. 5). But there is no significant difference of serum IL8 among different genotypes.

\section{Discussion}

Retrotransposons are dominant components in most land plant and mammals genomes [20, 28, 43] and regarded as important drivers of species diversity and putative actors in evolution and adaptation [28, 44-46]. In domestic animals, RIPs have been applied for the analysis of genetic diversity and evolution, and variety identification, and display great potentials in animal genetics and molecular breeding (e.g. sheep [32], 

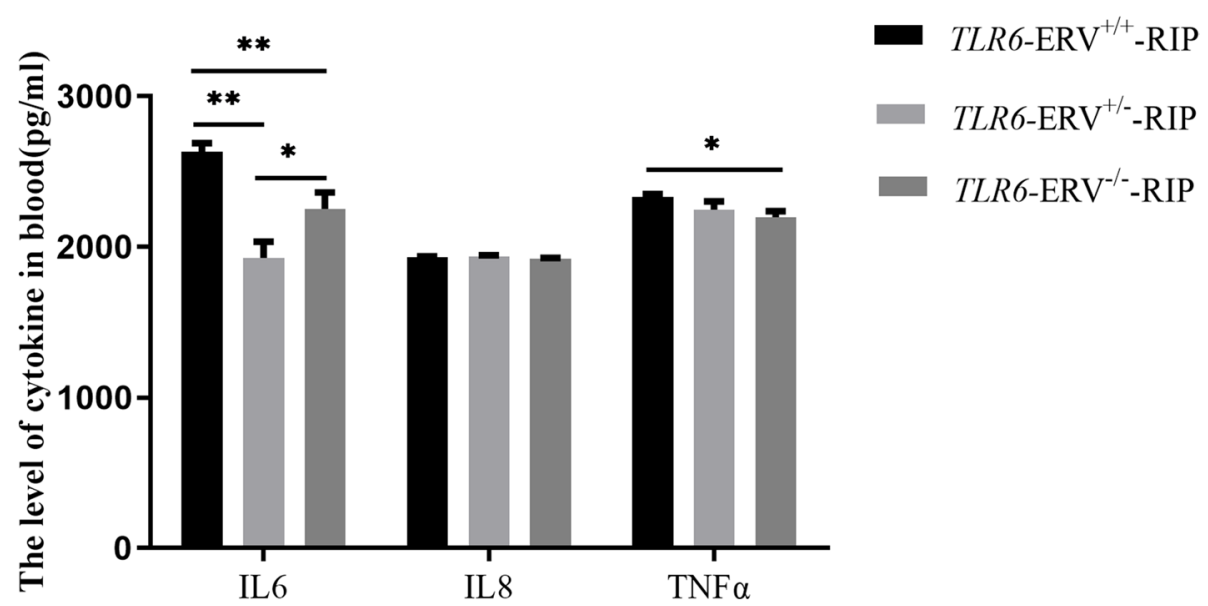

All measurements were performed in 4 or 5 replicates for each animal. Values shown are mean \pm SD.* showed $p<0.05$; ${ }^{* *}$ showed $p<0.01$

chicken [34], and miniature pigs [47]). Our previous study revealed that LINE, LTR, and SINE are the major components in the pig genome, and totally account for about $37.13 \%$ of the genome sequence [42]. According to the insertion age analysis, differential evolution profiles were observed for different families and subfamilies of retrotransposons. Most retrotransposons in the pig genome are ancient and no longer jumping, and cannot generate polymorphic insertions in current populations, whereas some of them were thought to be younger retroelements, such as SINEA, L1D, ERV6 subfamilies [42]. These retrotransposons still play roles in shaping genome and gene evolution and contribute to the genomic variations and their insertions tend to generate polymorphisms, which can be used as genetic markers. In addition, it has been suggested that transposable elements affect the genome in both destructive and constructive ways [43]. In this study, we predicted 32 RIPs and finally identified five RIPs in TLRs genic and flanking regions by sequence alignment combined with PCR validation and Sanger sequencing. The success rate of experimental validation of the in silico predicted RIPs by PCR was low $(15.62 \%, 5 / 32)$. By careful manual inspection of the input sequences we found that the main reason is a deficient assembly of the non-refence genomes, because most predicted RIPs that failed to be confirmed by PCR were located in gaps. Five identified RIPs reside in different genic positions including introns, 5' and 3' flanking regions of TLRs. Two ERV insertions-one of $192 \mathrm{bp}$ and the other of $413 \mathrm{bp}$ in length-were identified in the first intron of TLR6 and TLR7, respectively. Based on the bioinformatic analysis, the 192 bp ERV insertion in the intron 1 of TLR6 was predicted to be near the putative core promoter region indicating that it may be involved in gene regulation. In fact, since the ERV LTR contains the U3-R-U5 sequences, which are considered as transcriptional regulators because of the U3 region [48], it may act as an enhancer or promoter [49-51]. Here, the luciferase reporter assay provides experimental evidence supporting potential enhancer function of the $192 \mathrm{bp}$ ERV insertion. Our results show that the ERV element is not only able to increase the TLR6 promoter activity, but can also enhance the activity of diverse mini-promoters.

Population genetic analysis of the confirmed RIPs revealed that most loci are in Hardy-Weinberg equilibrium, while some polymorphic insertion loci (e.g. TLR6-ERV-RIP in Sujiang and Fengjing) show departure, indicating that these may be under selection possibly due to their impact on immune response or other biological function. The deletion allele of TLR6-ERVRIP was found exclusively in Chinese native pig breeds (Bama and Fengjing) or cross breeds containing genetics of Chinese pigs such as Sujiang (Duroc $\times$ Jiangquhai $\times$ Fengjing), while all analyzed western pig breeds including Landrace, Yorkshire, Duroc, and Sicilian Black from Italy are monomorphic and only contain the ERV insertion allele $\left(E R V^{+}\right)$. This finding suggest that the deletion allele $\left(E R V^{-}\right)$likely originates from Asian pig breeds. Based on the impact of this RIP on immune response as shown by expression analysis of the genes of TLR signaling pathway and serum cytokine measurement (see below), it can be used to improve disease resistance (such as Sujiang) or can be introduced into Chinese native breeds using marker assisted selection. However, the association with immune response still needs further confirmation in a larger cohort.

Piglets used in this study for the analysis of the immune response were 30 days old which represents an important 
stage for the development of the adaptive immunity in pigs [52]. We used samples from different tissues of these piglets, carrying different ERV insertion genotypes, to evaluate the expression of TLR6 and TLR1, which is a neighboring gene of TLR6 located only $4.2 \mathrm{~kb}$ away. The qPCR analysis demonstrated that the ERV insertion was significantly associated with enhanced mRNA expressions of TLR6 and TLR1 in multiple tissues of 30 dayold piglets $(p<0.05)$. TLRs play important roles in the innate immune response by recognizing pathogens. They interact with adapter molecules, such as MyD88, TIRAP, Rac1 and Tollip, which are downstream genes of the TLR signaling pathway, to drive the immune responses via the activation of transcription factor $\mathrm{NF}_{\mathrm{KB}} \mathrm{B}$ and the production of downstream inflammatory cytokines [53-55]. The cytokines, such as IL6 and IL8, released by inflammatory cells are essential factors in resisting pathogen infection. Using qPCR analyses, we further confirmed that the ERV insertion is associated with upregulation of several downstream genes of the TLR signaling pathway in multiple tissues of 30 day-old piglets, suggesting that the ERV insertion may not only increase the expressions of TLR6 and TLR1, but also enhance the expression of their downstream genes.

Higher TLR1 expression suggested better prognosis in patients with pancreatic ductal adenocarcinoma $(P D A C)$ [56]. The mRNA expression of major TLR genes including TLR1 and TLR6 of Tibetan pigs was higher in most immune tissues compared to Yorkshire pigs, which may result in stronger innate immunity of Tibetan pigs [57]. Higher expression of TLRs was also associated with stronger disease resistance [55]. Yorkshire $\times$ Landrace (YL) pigs exhibited more serious clinical symptoms when artificially infected with porcine circovirus type 2 (PCV2) virus compared with Laiwu, which is a Chinese native pig breed, indicating YL and Laiwu pigs display different susceptibility to PCV2 infection and Laiwu pigs seem to be more resistant to PCV2 virus. The serum levels of IL6, IL8, IL12 and Transforming growth factor beta 1 (TGF $\beta 1$ ) showed a more pronounced increase at the early infection stages with the PCV2 virus in the Laiwu pigs compared to YL pigs [58]. Here, consistent with the increased expression of genes in the TLR signaling pathway due to ERV insertion, we also found upregulated expression of the important inflammatory factors including $I L 6, I L 8$, and $T N F \alpha$. We validated this finding by measuring serum cytokine levels and found significantly higher concentration of IL6 and TNF $\alpha$ in $\mathrm{ERV}^{+/+}$ piglets. Taken together, these data provide evidence that the 192 bp ERV insertion may upregulate the expression of TLR6, TLR1, and their downstream genes by acting as an enhancer involved in the regulation of TLR signaling pathway, which may not only alter the gene activities in the TLR signaling pathway and inflammatory factors, but also cause individual variation during the immune response. However, further confirmation of the influence of this allele on genetic and phenotypic variation is highly recommended. In detail, future experiments in additional samples and on a more functional side should be considered to draw a more solid conclusion of the causality. Moreover, association with the phenotypes should be evaluated before determining that this marker should be included in selection schemes for disease resistance.

\section{Conclusions}

By using bioinformatic analysis and PCR-based verification, five RIPs, located in the 3' flanking sequence of TLR3 gene, 5' flanking region of TLR5 gene, intron 1 of TLR6 gene, intron 1 of TLR7 gene, and 3' flanking region of TLR8 gene, were identified and differential distribution in diverse pig breeds was observed. The 192 bp ERV insertion in the intron 1 of TLR6 significantly increases the activity of the TLR6 promoter and two mini-promoters acting as an enhancer $(p<0.05)$. Furthermore, the ERV insertion was also significantly associated with enhanced expression of TLR6 and TLR1, downstream genes (MyD88, Rac1, TIRAP, and Tollip) of TLR signaling pathway and inflammatory factors (IL6, IL8, and TNF $\alpha$ ) in diverse tissues of 30 day-old piglets, as well as higher serum concentrations of IL6 and TNF $\alpha(p<0.05)$. Thus, the $192 \mathrm{bp}$ ERV insertion allele may be beneficial for the immune response and useful for molecular breeding of disease resistant animals.

\section{Material and methods RIP screen}

Ten TLR genes and their flanking sequences (5 kb 5' upstream and $3 \mathrm{~kb}$ 3' dowstream) were obtained from fifteen assembled non-reference genomes (Landrace, Yorkshire, Pietrain, Berkshire, Hampshire, Cross-breed of Yorkshire/Landrace/Duroc, Wuzhishan, Tibetan, Rongchang, Meishan, Bamei, Bama, and Jinhua, Goettingen, and Ellegaard Gottingen minipigs) and one reference genome (Duroc) deposited in the NCBI database (https://www.ncbi.nlm.nih.gov/) to screen for structural variations by sequence alignment using the ClustalX program. Large structural variations (more than $50 \mathrm{bp}$ long) present in just one population among sixteen population were retained for further analysis. Retrotransposon (SINE, LINE, and ERV) insertions were annotated by RepeatMasker (http://www.repea tmasker.org/) with a customer constructed library [42]. Promoters were predicted in BDGP (https://fruit fly.org/seq_tools/promoter.html), ENCODE (https:// www.encodeproject.org/), and Promoter 2.0 Prediction 
Server (http://www.cbs.dtu.dk/services/Promoter/). Putative transcription factor binding sites were determined in silico using the online tool PROMO (http:// alggen.lsi.upc.es/cgi-bin/promo_v3/promo/promoinit. cgi?dirDB=TF_8.3). The predicted large structural variations (more than $50 \mathrm{bp}$ ) overlapping with retrotransposon (SINE, LINE, and ERV) insertions were designated as RIPs. These RIPs were further experimentally validated in seven Chinese native pig breeds (Diannan small-ear Pigs, Erhualian, Wuzhishan, Bama, Tibetan, Meishan, Fengjing Pigs), three commercial pig breeds (Duroc, Landrace, Yorkshire), one cross breed (Sujiang) and wild boars (from Anhui province, Fujian province and Heilongjiang province) by PCR amplification and fragment analysis (Vazyme, Nanjing, China). For each breed, two pooled DNA samples were used, and each pool $(50 \mathrm{ng} / \mathrm{ul})$ contained three individual samples. Total DNA was isolated from ear or blood samples of each animal using the TIANamp Genomic DNA Kit (Tiangen, Beijing, China). The quality and concentration of the DNA were measured using a spectrophotometer (NanoPhotometer N60 Touch, Implen Gmbh, Germany) and by running the samples on $0.8 \%(\mathrm{w} / \mathrm{v})$ electrophoretic gel. Each DNA sample was diluted to $50 \mathrm{ng} / \mathrm{ul}$ in concentration for pool mixture. Details on samples and primers used for RIP evaluation are listed in Table S2 and Table S3. All obtained RIPs were further confirmed by TA cloning (Tiangen, Beijing, China) following the manufacturer's instructions and sequencing at TsingKe Bological Technology Co. Ltd (Nanjing, China).

\section{RIP Genotyping}

In total twelve breeds (Duroc, Landrace, Yorkshire, Erhualian, Meishan, Fengjing, Bama, Tibetan, Wuzhishan, Sujiang, and Sicilian black) were used to examine the RIP distribution; the number of animals used for each breed and breed origins is listed in Table S2. Among these breeds, Duroc, Landrace, and Yorkshire are three lean type breeds, Sicilian Black, Erhualian, Meishan, and Fengjing are four fat type pigs and Bama, Wuzhishan, and Tibetan are three miniature pigs. Erhualian, Meishan, Fengjing, Bama, Tibetan, Wuzhishan, are Chinese native breeds, while Sujiang is a synthetic line with 62.5\% Duroc, 18.75\% Jiangquhai, and 18.75\% Fengjing proportion. Sicilian Black is an Italian native breed. The genotype and the allele frequencies were calculated, and Hardy-Weinberg equilibrium were tested using POPGENE [59]. Polymorphic information content (PIC) was calculated by the formula:

$$
P I C=1-\sum_{i=1}^{m} P_{i}^{2}-\sum_{i=1}^{m-1} \sum_{j=i+1}^{m} 2 P_{i}^{2} P_{j}^{2}
$$

\section{Dual luciferase reporter assay}

One predicted promoter region (NC_010450.4, 31,167,521-30,168,515) of TLR6 with (1187 bp) and without the ERV insertion allele (995 bp) was cloned from the Sujiang genomic DNA (primers were listed in Table S3), and verified by sequencing. Then the clones were inserted into the pGL3-basic vectors (Promega, Madison, American) to construct $T L R 6^{\mathrm{ERV}+}$-Luc (En) vector and $T L R 6^{\mathrm{ERV}-}$ Luc (En) Vector. In addition, $\beta$-globin and Oct 4 minipromoters were cloned from pEDV- $\beta$-globin-GFP and pTol2-Oct4-mCherry vector, respectively [60] and inserted into the pGL3-basic vectors with or without the $192 \mathrm{bp}$ ERV for enhancer activity evaluation. A total of $2 \times 10^{4}$ PK15 and Hela cells were plated in a 24-well plates and transfected with the plasmids by using Lipofectamine 3000 reagent (Invitrogen, Carlsbad, American). After 48 h, cells were collected for luciferase activity evaluation by using the dual luciferase reporter system (Promega, Madison, American) according to the manufacturer's protocol.

\section{Expression analysis}

The Sujiang piglets were genotyped and five 30 day-old piglets for each genotype $\left(\mathrm{ERV}^{+/+}, \mathrm{ERV}^{ \pm}\right.$, and $\left.\mathrm{ERV}^{-/-}\right)$ were selected and slaughtered to collect tissue samples including liver, lung, kidney, and spleen. The mRNA samples were extracted and cDNAs were prepared according to the manufacturer's protocol by using TAKARA Kit (Takara, Tokyo, Japan). Then, the mRNA expressions of TLR6, TLR1, MyD88, RAC1, Tollip, TIRAP, TNFa, IL6, and IL8 mRNA were evaluated by quantitative real-time PCR (qPCR) using the 7900HT Fast Real-Time PCR System (Applied Biosystems, New York, American) in a total volume of $20 \mu \mathrm{l}$ containing SYBR mix $(10 \mu \mathrm{l})$, primers $(4 \mathrm{ng})$, and cDNA sample (50 ng) according to the manufacturer's instructions (Takara,Tokyo, Japan). All measurements were performed in 3 replicates. Glyceraldehyde-3-phosphate dehydrogenase (GAPDH) was used as an endogenous control to normalize the target gene expression in four different tissues. Gene expression was measured using the $2^{-\Delta \Delta C t}$ method. PCR products were run on $1.5 \%$ ethidium bromide-stained agarose gels and confirmed using melting curve analyses to assess PCR product quality.

\section{Measurement of serum TNFa, IL6, and IL8 by enzyme linked immunosorbent assay (ELISA)}

TNF $\alpha$, IL6, IL8 concentration in serum of 30 day-old Sujiang piglets for each genotype $\left(\mathrm{ERV}^{+/+}, \mathrm{ERV}^{ \pm}\right.$, and $\mathrm{ERV}^{-l-}$ ) were measured using the pig TNF $\alpha$, IL6, and IL8 
ELISA Kit (Solarbio Science, Beijing, China) by following the manufacturer's protocol. All measurements were performed in 4 or 5 replicates, and mean values were used for statistical analysis.

\section{Statistical analysis}

Experimental results were processed by statistical SPSS17.0 software package (SPSS, Chicago, USA) using one-way analysis of variance with Tukey's post hoc test, and the data were expressed as mean \pm SD.

\section{Animal welfare}

All treatments and protocols involving animals in this study were strictly done in accordance with the guidelines of the Animal Experiment Ethics Committee of Yangzhou University (approval number: YZUDWSY2018-12).

\begin{abstract}
Abbreviations
TLRs: Toll-like receptors; RIPs: Retrotransposon insertion polymorphisms; QTL: Quantitative trait locus; ERV: Endogenous retrovirus; PCR: Polymerase chain reaction; MyD88: Myeloid differentiation factor 88; Rac1: Rac family small GTPase 1; TIRAP: TIR domain containing adaptor protein; Tollip: Toll interacting protein; IL6: Interleukin 6; IL8: Interleukin 8; TNFa: Tumor necrosis factor alpha; IFN-a: Interferon alpha 1; LTR: Long Terminal Repeat elements; SINE: Short Interspersed Nuclear Elements; ELISA: Enzyme linked immunosorbent assay; IRAP: Inter-retrotransposon amplified polymorphism; REMAP: Retrotransposon-microsatellite amplified polymorphism; NFkB: Nuclear factor kappa B subunit; PDAC: Pancreatic ductal adenocarcinoma; PCV2: Porcine circovirus type 2; TGF $\beta 1$ :Transforming growth factor beta 1 .
\end{abstract}

\section{Supplementary Information}

The online version contains supplementary material available at https://doi. org/10.1186/s13100-021-00248-w.

Additional file 1: Table S1. Predicted Structural variations (SVs) of pig TLRs. Table S2 Number and origin of pig breeds for TLRs RIPs detection. Table S3 The primers for PCR, vectors construction and q-PCR.

\section{Authors' contributions}

C.S. conceived the project; X.W. participated in its design; Z.C., E.M., E. D., Y.A. and C. C. performed animal trial, laboratory experiments, data collection and statistical analysis. X.W. and C.S. drafted the manuscript. K.L., G.G. and K. $W$. assisted in study design and review manuscript. The author(s) read and approved the final manuscript.

\section{Funding}

This work was supported by the National Natural Science Foundation of China (31872977, 32002146), China Postdoctoral Science Foundation (2020M671630), and the Jiangsu Agriculture Science and Technology Innovation Fund [CX(19)2016]; and the Priority Academic Program Development of Jiangsu Higher Education Institutions and the High-end Talent Support Program of Yangzhou University.

\section{Availability of data and materials}

All data needed to evaluate the conclusions in this paper are present either in the main text or the Supporting information.

\section{Declarations}

Ethics approval and consent to participate Not applicable.
Consent for publication

Not applicable.

\section{Competing interests}

The authors declare that they have no competing interest.

\section{Author details}

${ }^{1}$ College of Animal Science \& Technology, Yangzhou University, Yangzhou 225009, Jiangsu, China. ${ }^{2}$ Leibniz Institute for Farm Animal Biology (FBN), 18196 Dummerstorf, Germany. ${ }^{3}$ Department of Veterinary Science, Unit of Animal Production, University of Messina, 98168 Messina, Italy. ${ }^{4}$ Institute of Animal Science, Chinese Academy of Agricultural Sciences, 100081 Beijing, China.

Received: 8 November 2020 Accepted: 23 July 2021

Published online: 18 August 2021

\section{References}

1. Medzhitov R. Toll-like receptors and innate immunity. Nat Rev Immunol. 2001;1(2):135-45. https://doi.org/10.1038/35100529.

2. Medvedev AE. Toll-like receptor polymorphisms, inflammatory and infectious diseases, allergies, and cancer. J Interf Cytokine Res. 2013;33:467-84. https://doi.org/10.1089/jir.2012.0140.

3. Vijay K. Toll-like receptors in immunity and inflammatory diseases: Past, present, and future. Int Immunopharmacol. 2018;59:391-412. https://doi. org/10.1016/j.intimp.2018.03.002.

4. Dvornikova KA, Bystrova EY, Platonova ON, Churilov LP. Polymorphism of toll-like receptor genes and autoimmune endocrine diseases. Autoimmun Rev. 2020;19(4):102496. https://doi.org/10.1016/j.autrev.2020. 102496.

5. Hawn TR, Wu H, Grossman JM, Hahn BH, Tsao BP, Aderem A. A stop codon polymorphism of Toll-like receptor 5 is associated with resistance to systemic lupus erythematosus. Proc Natl Acad Sci U S A. 2005;102(30):10593-7. https://doi.org/10.1073/pnas.0501165102.

6. Quach H, Rotival M, Pothlichet J, Loh YHE, Dannemann M, Zidane N, et al. Genetic adaptation and neandertal admixture shaped the immune system of human populations. Cell. 2016;167(3):643-56. https://doi.org/ 10.1016/j.cell.2016.09.024.

7. Dutta SK, Tripathi A. Association of toll-like receptor polymorphisms with susceptibility to chikungunya virus infection. Virology. 2017;511:207-13. https://doi.org/10.1016/j.virol.2017.08.009.

8. Novák K. Functional polymorphisms in Toll-like receptor genes for innate immunity in farm animals. Vet Immunol Immunopathol. 2014;157(12):1-2. https://doi.org/10.1016/j.vetimm.2013.10.016.

9. Cinar MU, Hizlisoy H, Akyüz B, Arslan K, Aksel EG, Gümüşsoy KS. Polymorphisms in toll-like receptor (TLR) 1, 4, 9 and SLC11A1 genes and their association with paratuberculosis susceptibility in Holstein and indigenous crossbred cattle in Turkey. J Genet. 2018;97(5):1147-54.

10. Elmaghraby MM, El-Nahas AF, Fathala MM, Sahwan FM, Tag EL-Dien MA. Association of toll-like receptors 2 and 6 polymorphism with clinical mastitis and production traits in Holstein cattle. Iran J Vet Res. 2018;19(3):202-7.

11. Fouad NA, Saeed AM, Mahedy AW. Toll like receptor-4 gene polymorphism and susceptibility to pulmonary tuberculosis. Egypt J Immunol Egypt. 2019;26:1-10.

12. Uenishi H, Shinkai H. Porcine Toll-like receptors: The front line of pathogen monitoring and possible implications for disease resistance. Dev Comp Immunol. 2009;33:353-61. https://doi.org/10.1016/j.dci.2008.06. 001.

13. Shinkai H, Okumura N, Suzuki R, Muneta Y, Uenishi H. Toll-like receptor 4 polymorphism impairing lipopolysaccharide signaling in Sus scrofa, and its restricted distribution among Japanese wild boar populations. DNA Cell Biol. 2012;31 (4):575-81. https://doi.org/10.1089/dna.2011.1319.

14. Yang XQ, Murani E, Ponsuksili S, Wimmers K. Association of TLR4 polymorphism with cytokine expression level and pulmonary lesion score in pigs. Mol Biol Rep. 2012;39(6):7003-9. https://doi.org/10.1007/ s1 1033-012-1530-2.

15. Yang X, Murani E, Ponsuksili S, Wimmers K. Association of TLR5 sequence variants and mRNA level with cytokine transcription in 
pigs. Immunogenetics. 2013;65(2):125-32. https://doi.org/10.1007/ s00251-012-0662-9.

16. Clop A, Huisman A, van As P, Sharaf A, Derdak S, Sanchez A. Identification of genetic variation in the swine toll-like receptors and development of a porcine TLR genotyping array. Genet Select Evol. 2016;48(1):28. https:// doi.org/10.1186/s12711-016-0206-0.

17. Darfour-Oduro K, Megens H, Roca A, Groenen M, Schook L. Evidence for adaptation of porcine Toll-like receptors. Immunogenetics. 2016:68(3):179-89. https://doi.org/10.1007/s00251-015-0892-8.

18. Muneta Y, Arai N, Yakabe Y, Eguchi M, Shibahara T, Sakuma A, Shinkai H, Uenishi H, Hirose K, Akiba M. In vivo effect of a TLR5 SNP (C1205T) on Salmonella enterica serovar Typhimurium infection in weaned, specific pathogen-free Landrace piglets. Microbiol Immunol. 2018;62(6):380-7. https://doi.org/10.1111/1348-0421.12591.

19. Zeng L, Pederson SM, Kortschak RD, Adelson DL. Transposable elements and gene expression during the evolution of amniotes. Mob DNA. 2018;9:17. https://doi.org/10.1186/s13100-018-0124-5.

20. Platt RN, Vandewege MW, Ray DA. Mammalian transposable elements and their impacts on genome evolution. Chromosom Res Chromosome Research. 2018;26:25-43. https://doi.org/10.1007/s10577-017-9570-z.

21. Chuong EB, Elde NC, Feschotte C. Regulatory activities of transposable elements: From conflicts to benefits. Nat Rev Genet. 2017;18(2):71-86. https://doi.org/10.1038/nrg.2016.139.

22. Orgel LE, Crick FHC. Selfish DNA: The ultimate parasite. Nature. 1980;284(5757):604-7. https://doi.org/10.1038/284604a0.

23. Hickey DA. Selfish DNA: A sexually transmitted nuclear parasite. Genetics. 1982;101(3-4):519-31.

24. Garcia-Perez JL, Widmann TJ, Adams IR. The impact of transposable elements on mammalian development. Dev. 2016;143(22):4101-14. https:// doi.org/10.1242/dev.132639.

25. Arkhipova IR, Yushenova IA, Angert E. Giant transposons in eukaryotes: Is bigger better? Genome Biol Evol. 2019;11:906-18. https://doi.org/10. 1093/gbe/evz041.

26. Kaaij LJT, Mohn F, van der Weide RH, de Wit E, Bühler M. The ChAHP complex counteracts chromatin looping at CTCF sites that emerged from SINE expansions in mouse. Cell. 2019;178(6):1437-1451.e1414. https://doi. org/10.1016/j.cell.2019.08.007

27. Kalendar R, Flavell AJ, Ellis THN, Sjakste T, Moisy C, Schulman AH. Analysis of plant diversity with retrotransposon-based molecular markers. Heredity (Edinb). 2011;106(4):520-30. https://doi.org/10.1038/hdy.2010.93.

28. Kalendar R, Amenov A, Daniyarov A. Use of retrotransposon-derived genetic markers to analyse genomic variability in plants. Funct Plant Biol. 2018;46(1):15-29. https://doi.org/10.1071/FP18098.

29. Payer LM, Burns KH. Transposable elements in human genetic disease. Nat Rev Genet. 2019;20(12):760-72. https://doi.org/10.1038/ s41576-019-0165-8.

30. Payer LM, Steranka JP, Yang WR, Kryatova M, Medabalimi S, Ardeljan D, Liu C, Boeke JD, Avramopoulos D, Burns KH. Structural variants caused by Alu insertions are associated with risks for many human diseases. Proc Natl Acad Sci U S A. 2017;114(20):E3984-92. https://doi.org/10.1073/pnas. 1704117114

31. Payer LM, Steranka JP, Ardeljan D, Walker J, Fitzgerald KC, Calabresi PA, Cooper TA, Burns KH. Alu insertion variants alter mRNA splicing. Nucleic Acids Res. 2019;47(1):421-31. https://doi.org/10.1093/nar/gky1086.

32. Chessa B, Pereira F, Arnaud F, Amorim A, Goyache F, Mainland I, Kao RR, Pemberton JM, Beraldi D, Stear MJ, et al. Revealing the history of sheep domestication using retrovirus integrations. Science. 2009;324(5926):5326. https://doi.org/10.1126/science.1170587.

33. Ngo MH, Arnal M, Sumi R, Kawasaki J, Miyake A, Grant CK, Otoi T, Fernández de Luco D, Nishigaki K. Tracking the fate of endogenous retrovirus segregation in wild and domestic cats. JVirol. 2019;93(24):e01324-01319. https://doi.org/10.1128/JVI.01324-19.

34. Pettersson ME, Jern P. Whole-genome analysis of domestic chicken selection lines suggests segregating variation in ERV makeups. Genes (Basel). 2019;10(2):162. https://doi.org/10.3390/genes10020162.

35. Rivas-Carrillo SD, Pettersson ME, Rubin C-J, Jern P. Whole-genome comparison of endogenous retrovirus segregation across wild and domestic host species populations. Proc Natl Acad Sci U S A. 2018;115(43):11012-7. https://doi.org/10.1073/pnas.1815056115.

36. Wragg D, Mwacharo JM, Alcalde JA, Wang C, Han JL, Gongora J, Gourichon D, Tixier-Boichard M, Hanotte O. Endogenous retrovirus EAV-HP linked to blue egg phenotype in Mapuche fowl. PLoS ONE. 2013;8(8): e71393. https://doi.org/10.1371/journal.pone.0071393.

37. Wang Z, Qu L, Yao J, Yang X, Li G, Zhang Y, Li J, Wang X, Bai J, Xu G, et al. An EAV-HP insertion in $5^{\prime}$ Flanking region of SLCO1B3 causes blue eggshell in the chicken. PLoS Genet. 2013;9(1): e1003183. https://doi.org/10. 1371/journal.pgen.1003183.

38. Li J, Davis BW, Jern P, Dorshorst BJ, Siegel PB, Andersson L. Characterization of the endogenous retrovirus insertion in CYP19A1 associated with henny feathering in chicken. Mob DNA. 2019;10:1-8. https://doi.org/10. 1186/s13100-019-0181-4.

39. Magotra A, Naskar S, Das B, Ahmad T. A comparative study of SINE insertion together with a mutation in the first intron of follicle stimulating hormone beta gene in indigenous pigs of India. Mol Biol Rep. 2015;42:465-70. https://doi.org/10.1007/s11033-014-3789-y.

40. Liu C, Ran X, Niu X, Li S, Wang J, Zhang Q. Insertion of 275-bp SINE into first intron of PDIA4 gene is associated with litter size in Xiang pigs. Anim Reprod Sci. 2018;195:16-23. https://doi.org/10.1016/j.anireprosci.2018.04.079.

41. Larkin MA, Blackshields G, Brown NP, Chenna R, Mcgettigan PA, McWilliam H, Valentin F, Wallace IM, Wilm A, Lopez R, et al. Clustal W and Clustal X version 2.0. Bioinformatics. 2007;23:2947-8. https://doi.org/10.1093/bioin formatics/btm404.

42. Chen C, Wang W, Wang X, Shen D, Wang S, Wang Y, Gao B, Wimmers $K$, Mao J, Li K, et al. Retrotransposons evolution and impact on IncRNA and protein coding genes in pigs. Mob DNA. 2019;10:1-24. https://doi.org/10. 1186/s13100-019-0161-8.

43. Kazazian HH Jr. Mobile elements: drivers of genome evolution. Science. 2004;303:1626-32. https://doi.org/10.1126/science.1089670.

44. Vicient CM, Casacuberta JM. Impact of transposable elements on polyploid plant genomes. Ann Bot. 2017;120(2):195-207. https://doi.org/10. 1093/aob/mcx078.

45. Orozco-Arias S, Isaza G, Guyot R. Retrotransposons in plant genomes: Structure, identification, and classification through bioinformatics and machine learning. Int J Mol Sci. 2019;20(15):3837. https://doi.org/10.3390/ ijms20153837.

46. Tollis $\mathrm{M}$, Boissinot $\mathrm{S}$. The evolutionary dynamics of transposable elements in eukaryote genomes. Genome Dyn. 2012;7:68-91. https://doi.org/10. $1159 / 000337126$.

47. Chen C, Wang X, Zong W, Enrico D, Domenico G, Guo Y, Mao J, Song C. Genetic diversity and population structures in chinese miniature pigs revealed by SINE retrotransposon insertion polymorphisms, a new type of genetic markers. Animals. 2021;11(4):1136. https://doi.org/10.3390/ ani11041136.

48. Christy RJ, Brown AR, Gourlie BB, Huang RC. Nucleotide sequences of murine intracisternal A-particle gene LTRs have extensive variability within the R region. Nucleic Acids Res. 1985;13(1):289-302. https://doi. org/10.1093/nar/13.1.289.

49. Feuchter-murthy AE, Freeman JD, Mager DL. Splicing of a human endogenous retrovirus to a novel phospholipase A2 related gene. Nucleic Acids Res. 1993;21(1):135-43. https://doi.org/10.1093/nar/21.1.135.

50. Schulte AM, Lai S, Kurtz A, Czubayko F, Riegel AT, Wellstein A. Human trophoblast and choriocarcinoma expression of the growth factor pleiotrophin attributable to germ-line insertion of an endogenous retrovirus. Proc Natl Acad Sci U S A. 1996:93(25):14759-64. https://doi.org/10.1073/ pnas.93.25.14759.

51. Beyer U, Moll-Rocek J, Moll UM, Dobbelstein M. Endogenous retrovirus drives hitherto unknown proapoptotic p63 isoforms in the male germ line of humans and great apes. Proc Natl Acad Sci U S A. 2011;108(9):3624-9. https://doi.org/10.1073/pnas.1016201108.

52. Butler JE, Wertz N. The porcine antibody repertoire: Variations on the textbook theme. Front Immunol. 2012;3:153. https://doi.org/10.3389/fimmu. 2012.00153.

53. Frazão JB, Errante PR, Condino-Neto A. Toll-like receptors' pathway disturbances are associated with increased susceptibility to infections in humans. Arch Immunol Ther Exp (Warsz). 2013;61 (6):427-43. https://doi. org/10.1007/s00005-013-0243-0.

54. Li X, Jiang S, Tapping RI. Toll-like receptor signaling in cell proliferation and survival. Cytokine. 2010;49(1):1-9. https://doi.org/10.1016/j.cyto.2009 08.010.

55. O'Neill LAJ, Golenbock D, Bowie AG. The history of Toll-like receptorsredefining innate immunity. Nat Rev Immunol. 2013;13(6):453-60. https://doi.org/10.1038/nri3446. 
56. Lanki M, Seppänen H, Mustonen H, Hagström J, Haglund C. Toll-like receptor 1 predicts favorable prognosis in pancreatic cancer. PLoS One. 2019;14(7):e0219245. https://doi.org/10.1371/journal.pone.0219245.

57. Cheng C, Sun WK, Liu R, Wang RM, Chen YH, Wang Y, Li JL, Lu XB, Gao R. Comparison of gene expression of Toll-like receptors and antimicrobial peptides in immune organs and tissues between Yorkshire and Tibetan pigs. Anim Genet. 2015;46(3):272-9. https://doi.org/10.1111/age.12286

58. Li Y, Liu H, Wang P, Wang L, Sun Y, Liu G, Zhang P, Kang L, Jiang S, Jiang Y. RNA-seq analysis reveals genes underlying different disease responses to porcine circovirus type 2 in pigs. PLoS ONE. 2016;11(5):e0155502. https:// doi.org/10.1371/journal.pone.0155502.

59. Yeh FC, Yang RC, Boyle T. POPGENE version 1.32: Microsoft Windowsbased freeware for population genetic analysis, quick user guide.
Edmonton: Molecular Biology and Biotechnology Centre, University of Alberta; 1999. p. 1-29.

60. Chan S, Shen D, Sang Y, Wang S, Wang Y, Chen C, Gao B, Song C. Development of enhancer-trapping and-detection vectors mediated by the Tol 2 transposon in zebrafish. PeerJ. 2019;7:e6862. https://doi.org/10.7717/ peerj.6862.

\section{Publisher's Note}

Springer Nature remains neutral with regard to jurisdictional claims in published maps and institutional affiliations.
Ready to submit your research? Choose BMC and benefit from:

- fast, convenient online submission

- thorough peer review by experienced researchers in your field

- rapid publication on acceptance

- support for research data, including large and complex data types

- gold Open Access which fosters wider collaboration and increased citations

- maximum visibility for your research: over 100M website views per year

At BMC, research is always in progress.

Learn more biomedcentral.com/submissions 